Session 1526

\title{
Industrial Partners Providing their Production Facility as an On-line Quality Control Laboratory
}

\author{
Ronald W. Garrett, Paul L. Stephenson, III \\ Grand Valley State University
}

\begin{abstract}
This initiative has resulted in the creation of a course in Statistical Process Control that incorporates uploading real-time quality data directly from the factory floor of a production facility operated by an industrial sponsor. Billions of dollars are spent each year by U.S. industry on equipment and systems that are necessary to manufacture sophisticated products which allow them to compete in the marketplace. The manufacturing companies that sponsor this project are very "pro-education" have agreed to support this project partly because they know that they are "data rich and analysis poor." Because they already own the manufacturing equipment and computers needed, the cost of passing data on to the university is small. Furthermore, they appreciate the benefits of a solution that is very portable. It can be readily used at other manufacturing sites and by other educational institutions.
\end{abstract}

For many years, students in geology, archeology, etc. have gone on field trips where they collect samples and perform analysis. However, engineering students traditionally have not had such opportunities. When these students walk into a manufacturing facility for the first time, they are impressed by the noise, heat and the sense of order. After and initial plant tour for this course, students are eager to see if they can understand and improve a real-world production process. Using this approach, students report that they learned much more than they would in a traditional college course since they are essentially performing as members of the quality control team for industry.

The paper that follows will describe the results of the two-year experience of using real-time quality data transferred from the factory floor and the reaction of students and sponsors. 


\section{Introduction}

Historically, when manufacturing engineering students visit a manufacturing facility for a plant tour, it is frequently a simple walk-through, rather akin to "window shopping." Although the kind of polite treatment afforded visitors would be expected, it is unusual to have a class of students invited to perform important analyses.

In the new course format used in Statistical Quality Methods (STA 314), a plant tour of the industrial site was conducted as part of the course before the course projects begin. This approach allowed students to observe a full-scale production facility and begin their understanding of the many facets of control of product quality. Throughout the semester the students uploaded "live" data from the operating production facility to complete their SPC projects. This continuously updated data can be transmitted and analyzed frequently throughout the day. As a result, students were assigned responsibilities equivalent to those of members of a quality control team for the industrial sponsor.

\section{Purpose of this Initiative}

Great sums of money are spent each year by U.S. industry to update and maintain the capital equipment that is necessary to manufacture a wide-range of sophisticated products which permit them to compete in the global marketplace. Even if universities could afford to purchase such machinery, they would not operate that type of equipment under full-scale production conditions. It is not their mission.

Unlike full-scale production, whenever manufacturing equipment is operated in a university environment, the primary goal is education or research. The manufactured parts produced are often unusable or unneeded and are frequently discarded as soon as they come off the machine. Often, numerous variables are fixed in order to show how changing one input variable at a time can affect the output. As a result, these laboratories do not reach the complexity of a full-scale production environment. 
The classical laboratory approach has the advantage that it is readily available to all students. However, traditional manufacturing engineering laboratories are operated in a well-controlled academic environment and the student's experience can be quite limited and, to some, even "sterile." Some complain that engineering laboratory experiences is confined to isolated experiments performed on stand-alone equipment. This can give an over-simplified view the production environment and distract the students from recognizing and investigating the wide range variables involving material, measurement, machine and humans that influence a full-scale production environment.

\section{Data Transmission}

Since a full-scale production facility is the centerpiece of this new course, real-time quality data was made available. Since computer labs were located just a few steps from their classroom, students were able upload data often and begin analyzing it immediately. The data was up-todate and unfiltered. Several advantages of the use of this "live" data were that the student could:

1) relate this data to the sights, sounds, and smells from the plant tour

2) be inquisitive and examine the complete problem, and

3) think about the type, quantity, and accuracy of the data collected.

The selection of a process to study was influenced by the availability of standard production equipment whenever meaningful data can be retrieved through existing computers and automatically sent to a site on the Internet (See Figure 1). The advances in digital computers and in Internet technology have made the transmission of data easier than originally anticipated.

\section{Student Visibility into the Problem}

Naturally, even the eloquent words spoken by well-meaning instructors about their experiences in a full-scale manufacturing environment are no substitute for direct involvement by students. Today, students can be over-stimulated by television, video games and even the Internet. Yet when these same students walk into a manufacturing facility for the first time, they are impressed by the noise, heat and sense of order. After a plant tour, our students were eager to have an 


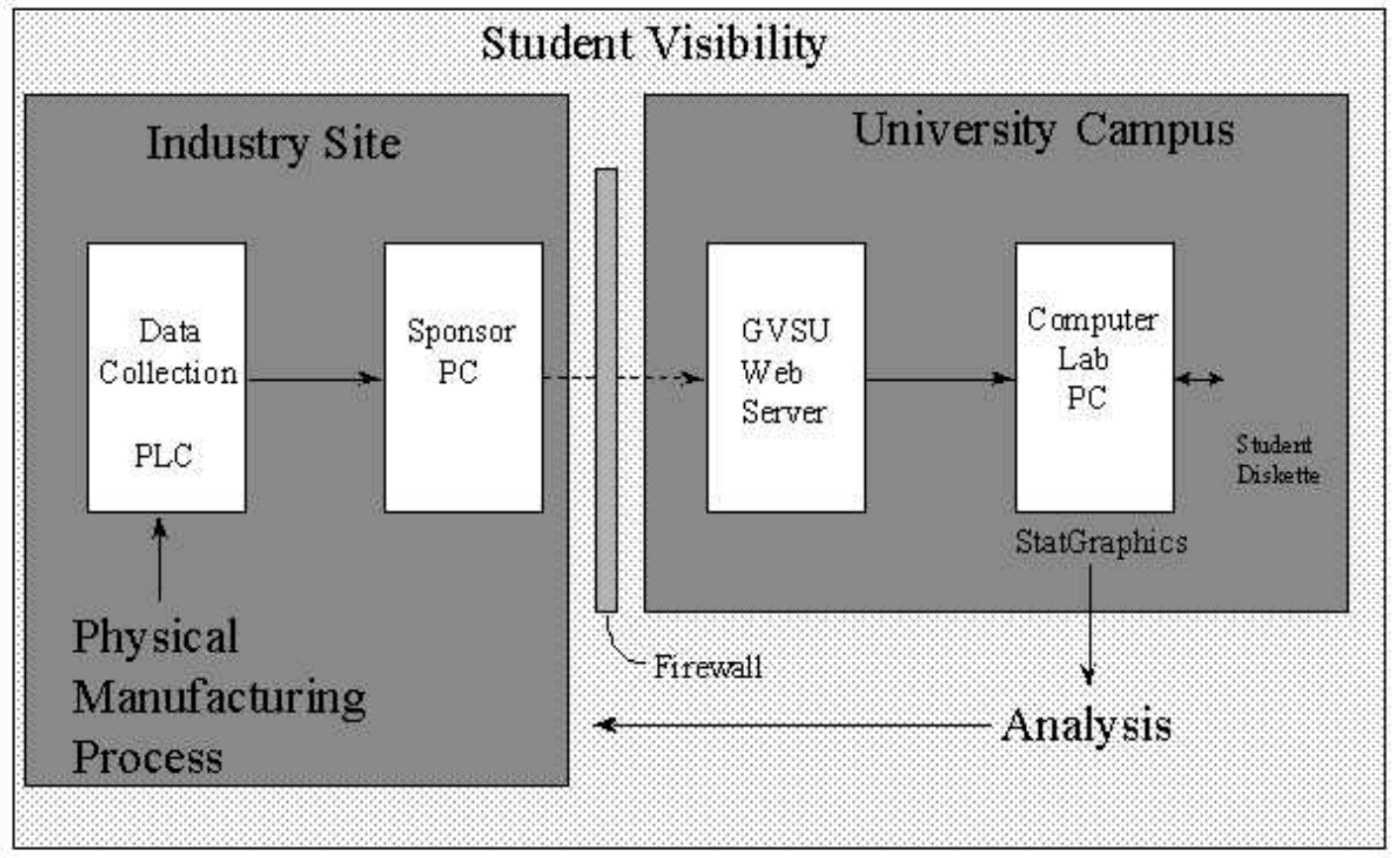

Figure 1 - Data Flow from Manufacturing Facility to Student Data Diskette

opportunity to try to see if they could improve the real-world production process. Since the students were able to interact with the "real thing", their development was more advanced. They received the opportunity to ask the kind of questions that can both help them learn more and make learning more enjoyable. Identifying these questions, being bold enough to ask, getting an answer, and deciding whether to probe further becomes an important part of their education. This environment not only motivates students to learn more, but can also teach students to be inquisitive. This experience becomes an important part of a comprehensive and well-rounded education.

The new Statistical Quality Methods course uses this new approach. This environment helps students to: think critically about a production process, collect informative data from a production process, apply standard statistical process quality control procedures, draw conclusions from these procedures, and communicate these findings to a non-mathematical audience. Our students have been able to grasp important practical issues in manufacturing involving communications, information accuracy, measurement, raw material variability, manufacturing process fluctuations, tool condition and human behavior. 


\section{Expectations for Students}

In the new course in Statistical Quality Methods, students were expected to:

1. understand how a physical product characteristic is affected by process variables,

2. gain an appreciation for the impact of undetected raw material flaws on quality and downtime,

3. realize the importance of the contribution made by individuals working on a production line,

4. acknowledge the organizational limitations of a typical manufacturing enterprise, and

5. recognize that a myriad of controllable and uncontrollable factors affect product quality, cost and production schedule.

Additional detail on expectations is provided in a companion paper titled by the authors ${ }^{[1]}$.

\section{Students See that their Opinions Matter}

Unfortunately, neither faculty lectures nor textbook examples give students a chance to see or touch the broad range of materials, tools, equipment, and processes involved in making finished parts and products. They cannot interact with the people making these parts. As a result, a student's ability to pursue areas of interest and curiosity is limited to the material presented in the textbook and introduced by the instructor. Students made oral presentations and submitted written reports to their professor and to quality control experts representing the industrial sponsor. This type of involvement facilitates the transition from college student to a role of greater responsibility.

\section{Sponsor Longevity Issues}

In order to achieve a Win/Win relationship with manufacturing companies that were part of the initiative, everyone needed to receive recognizable benefits. Some of the benefits needed to be tangible. The greatest success comes when benefits are received by both day-to-day sponsor contacts and the sponsor's top management. 
Some of the factors which encourage initial and continued participation of sponsors:

1. All of the industrial sponsors that have joined this project were very "pro-education" at a range of managerial levels. They each have track records showing support for projects in academia.

2. The industrial sponsors have indicated that this project was affordable. This is partly because they already have most or all of the equipment that was needed. Because existing data collection systems are utilized, the cost of passing on the data was small.

3. Because the industrial sponsors were providing data that was already being collected or was easy to collect, they can see that their risk in this initiative was relatively low.

4. Sponsors recognize that synergy was present. For example, several implementation problems experienced by one sponsor were solved by others.

5. The university took the leadership on this project and there was keen sponsor interest in participation just to see how our vision of future U.S. industry-university cooperation was realized.

The industry participants were responsible for: 1) operation, maintenance and modernization the production equipment, 2) for electronic data collection, and 3) for providing background information to faculty and students about products, processes and operating conditions.

Additionally, a specialist from the sponsor's organization participated in live classroom visits. The sponsor provided access to a contact person and student teams had contact by telephone and electronic mail.

VIII. Data Transmission Security

Making proprietary data available outside of a company was be resolved by simply removing proprietary identifiers from the data. Naturally, without specific identifiers, a person who finds this data on the Internet can only see rows and columns of numbers that have no particular meaning to them. They will not know enough about the context to know what they are seeing. 
Another concern that has been raised is about the security of a sponsor's computers. Our industrial sponsors have indicated that the method which we have proposed to provide the data will maintain the level of security that they require. Since production data is "pushed" from the sponsor's web server (See Figure 1), outside control of the sponsor's computers was eliminated. As a result, the university's Web Site serves as a buffer and "fire-wall." Additional security can be achieved by programming data transmission computers so that they are not connected to more than one other computer at a time.

\section{Affordability}

The software that was necessary was readily availability, and in several cases, was already purchased. This dramatically cut the implementation cost. The affordability of this type of system to the many small, new programs in manufacturing engineering and courses in applied statistics is one of the most important aspects of this project. Internet connections by universities and sponsors alike are commonplace today. There was a great opportunity today due to the increased capability of the computers residing on the factory floor and advances in computer networks. Potential sponsors exist in nearly every community.

\section{Workshop for Dissemination of Results}

Internet access has made the fruits of this initiative, including access to real-time production data from a full-scale production facility, available to colleges and universities all over the country.

A NSF funded workshop will be held in July 2000. At the workshop attendees will receive:

- an opportunity for an on-site visit to the full-scale production facility

- the software which was developed for data transmission,

- documentation (including a course outline, classroom exercises, system diagrams and other relevant information), and

- direct consultation with key players for this initiative.

The workshop will be focused on equipping attendees with knowledge of how to set up the computer infrastructure and how to manage plant tour expectations. Attendees will also be 
coached on practical issues like how to recruit and retain industry sponsors. Until an industrial sponsor becomes available locally, educational institutions can receive data from the GVSU Web server via the World Wide Web (http://engineer.gvsu.edu/faculty/garrettr/spc/) in order to utilize real-time data from a fully-operational production site.

\section{Conclusions}

This university-industry initiative shows how a new course in SPC where students could upload real-time quality data from the factory floor of a full-scale production facility operated by an industrial sponsor. Manufacturing companies acknowledge that they are "data rich and analysis poor." The cooperative climate between industry and universities has the potential to revolutionize the way that Statistical Process Control is taught.

Historically, because of distance, safety concerns and other logistical problems, students have not generally had an opportunity to: 1) participate in the operation and analysis of a full-scale production system that operates on a daily basis, 2) meet and interact with the actual people that operate the system, 3) offer recommendations to an industrial sponsor, and 4) see the results that their recommendations have on production quality. Since good data is a critical need in a SPC class, this project represents an opportunity for industry to share their vast equipment investment with colleges and universities.

Furthermore, the solution proposed is portable and can be readily used at similar institutions. The timing of this initiative is ideal because industry is more interested than ever in combining resources with academe to achieve global competitiveness.

\section{Acknowledgements}

The authors gratefully acknowledge the support of the National Science Foundation, the Society of Manufacturing Engineers, Grand Valley State University and an industry consortium of west Michigan area manufacturing companies.

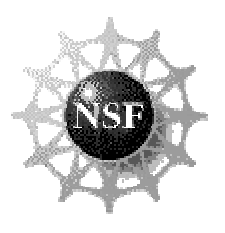


Bibliography

1. Stephenson, P. L. and Garrett, R. W. "How a Course in Statistical Process Control Can Utilize Real-time Data from an Industrial Production Facility", Proceedings from the ASEE Annual Conference, June 2000.

\section{RONALD W. GARRETT}

Dr. Garrett received his B.S. and M.S. in Mechanical Engineering at Purdue University and a Ph.D. from the University of Cincinnati. His recent consulting and research has been in Design for Manufacturability and manufacturing systems engineering. After serving on the faculty of the College of Applied Science at University of Cincinnati, he spent over 10 years in R \& D, design and manufacturing engineering at General Motors, AlliedSignal and Litton Industries. Dr. Garrett is currently a Professor of Engineering at Grand Valley State University (garrettr@gvsu.edu) where he teaches engineering design and manufacturing engineering courses. He is a Registered Professional Engineer in Michigan and Ohio.

\section{PAUL L. STEPHENSON, III}

Dr. Stephenson received his M.S. in Mathematical Sciences and Ph.D. in Management Sciences at Clemson University. His areas of expertise are quality control and design of experiments. While at Clemson University he served as an editorial assistant for the Journal of Quality Control. Dr. Stephenson is currently an Assistant Professor of Mathematics and Statistics at Grand Valley State University (stephenp@gvsu.edu) where he teaches introductory statistics, statistical process quality control, and design of experiments. He is a member of the American Statistical Association. 